\title{
DENTAL CARE HABITS OF RURAL CONSUMERS IN TELANGANA
}

\begin{tabular}{|l|l|}
\hline M. Madhavi, & M. Rajanikanth, \\
Associate Professor, & Associate Professor, \\
Einstein College of Business Management, & Einstein College of Business Management, \\
Nadergul & Nadergul \\
Koppula.sm.29@gmail.com & rajanikanthreddym@gmail.com \\
\hline
\end{tabular}

\begin{abstract}
An important and recent development in India's consumerism is the emergence of the rural market for several basic consumer goods. Three-fourths of India's population lives in rural areas, and contribute onethird of the national income. The mouth is a mirror that can reflect the health of the rest of your body. Numerous recent studies investigating the mouth-body connection have suggested an association between oral health and general health. Research has shown that dental diseases can best be prevented through early detection and primary prevention. Which means people need to, at least get the basics right - brush twice daily and visit a dentist twice a year. The benefit of doing so is not only less painful, but also significantly less expensive. Children, right from the age of three should be made aware of basics like the importance of brushing teeth twice a day, cleaning teeth and gums properly and other oral care information. Starting early will make oral hygiene not a practice but a habit with them. In this context the present study has been conducted to know the basic dental care habits of rural consumers in Telangana area. It was conducted in Karimnagar and RangaReddy districts of Telangana State. A Pre-structured questionnaire was used to collect the primary data from a sample of 150, 75 from each district. The study has shown that still some traditional methods are used in rural areas to clean their teeth and visiting a dentist is not a regular activity among them. The study suggests business people to encourage good habits of dental care which will increase their business too.
\end{abstract}

Keywords: Consumer habits, Dental care, Dental hygiene, Rural consumer.

Introduction: Mouth is the gateway and place of disease for microbial infections that affect the health of a human being. It reflects the health of the whole body as a mirror. Studies have shown that there is a relationship between oral health and general health For instance, there is a growing body of evidence indicating that chronic gum disease may contribute to the development of heart disease, said Dr. Ashok Dhoble, Secretary General, Indian Dental
Association, Head Office. So we can say one cannot be healthy without good oral health. It is proven that dental diseases can be prevented can best be prevented if they are identified in the early stages and with primary prevention. The prevention can be done if people make basic habits like brushing twice a day, visiting a dentist every six months etc., which are painless and less expensive. Children below three years, if habituated to brushing twice, knowing the 
ELK

Asia Pacific Journals

importance of cleaning teeth and gums, and oral care information, it is easy to prevent dental problems as well as many body related problems. (Dr. Bhagwant Singh, National President, Indian Dental association).

Need and Importance of the study: In this regard the present study was conducted to know the awareness of basic dental habits of rural consumers of Telangana.

\section{Major Objectives:}

1. To know the measures to be taken by rural consumers of Telangana for oral and dental hygiene

2. To study the accessories used for dental care by these rural people.

3. To find out the measures taking for dental care and to what extent these rural consumers are visiting a dentist

4. To know the consumer attitudes towards their dental care.

5. To find which is the leading oral care brand in rural areas of Telangana

\section{RESEARCH METHODOLOGY}

Scope of the study: The study was conducted in rural areas of RangaReddy and Karimnagar districts. The scope is restricted to the dental care habits of consumers.
ELK Asia Pacific Journals - Special Issue ISBN: 978-81-930411-9-2

Research Design: The study was aimed to know dental care habits of rural people, so descriptive research design was used, as descriptive research design aims to know the market characteristics like what, where, when, who, why and how.

Sampling Design: Convenience sampling method was used to collect the data from the respondents, with a view that the sample has to cover all age groups, gender and social status. The respondents were caught at different places like their homes, farms, bust stops etc. The sample size was chosen as 150, 75 from each district. The sample covered 5 villages from each district, chosen randomly.

\section{NATURE AND SOURCES OF DATA:}

The detailed information required for the study was collected from both primary and secondary sources in order to accomplish objectives of the study. Primary data were collected with the help of a pre-structured questionnaire and direct interview method. The secondary data were collected from Journals, Newspapers, Magazines and Websites. The questionnaire was prepared based on the secondary data and was validated with the help of a pilot study conducted in Nadergul village of Ranga Reddy district with a sample size of 30 . The 
ELK

Asia Pacific Journals

questionnaire was translated in to Telugu

before administering it to respondents.

Data Analysis: The data was analyzed using simple tabulation and percentages.

Limitation: The study aimed to know the basic dental care habits of rural people and does not cover all the areas of dental care. The study was conducted in only two districts of Telangana, which may not represent the whole.

LITERATURE REVIEW: Dental care has been a part of Human health from the ancient times. Oral diseases continue to be a major health problem world-wide. Oral health is integral to general well-being and relates to the quality-of-life that extends beyond the functions of the craniofacial complex. India is a rapidly developing nation and is making great progress in IT, finance and living standard. In spite of these, it is very sad to know that very few people believe in regular dental care ${ }^{1}$ Dental diseases restrict the activities in School, Work and Home and significantly diminish the quality of life in children and adults, especially in low-income groups ${ }^{2}$. Tooth brushing may help prevent some oral health diseases considered to be public health problems--in particular, certain presentations
ELK Asia Pacific Journals - Special Issue

ISBN: 978-81-930411-9-2

of chronic periodontal diseases and dental caries $^{3}$.

Oral hygiene includes the following:

Teeth Cleaning: Teeth cleaning involve removal of dental plaque and tartar from teeth to prevent cavities, gingivitis, and gum disease. Dentists recommend that teeth be cleaned professionally at least twice every year.

Tongue Cleaning: it is a part of oral care as it removes bacterial coating on tongue that generates bad breath and problems to teeth and gums.

Gum care: Massaging gums is generally recommended for good oral health. It is recommended to brush and floss at least two times everyday to maintain a healthy dentition.

Toothbrush: The toothbrush is a fundamental tool used for accomplishing the goals of plaque control. It is the most common device used for maintaining good oral hygiene. "An ideal toothbrush may be defined as the one which removes plaque effectively."

Frequency of changing toothbrush: It is suggested that the toothbrush be changed every three months or even before if the bristles appear frayed or "flowered". The 
ELK

Asia Pacific Journals

correct brushing technique includes following steps

Toothpaste: Toothpaste is a paste or gel dentifrice used to clean and improve the aesthetic appearance and health of teeth. It is almost always used in conjunction with a toothbrush. Toothpaste use can promote good oral hygiene. It can aid in the removal of dental plaque and food from the teeth, it can aid in the elimination and /or masking of halitosis, and it can deliver active ingredients such as fluoride to prevent tooth and gum disease.

Mouthwash: Mouthwash or mouth rinse is a product used for oral hygiene. Antiseptic and anti-plaque mouth rinse claims to kill the germs that cause plaque, gingivitis, and bad breath. Anti-cavity mouth rinse uses fluoride to protect against tooth decay.

Dental floss: Dental floss is either a bundle of thin nylon filaments or a plastic (teflon or polyethylene) ribbon used to remove food and dental plaque from teeth.

Vibration: Some flossing wands utilize vibration which transfers through the floss, originating from the ends. The movement would also help in temporarily separating tooth and gum for floss to get through.

There were different ways of brushing and caring methods mentioned in Indian culture.
ELK Asia Pacific Journals - Special Issue

ISBN: 978-81-930411-9-2

People used to chew the twigs of neem, Miswak(Salvadora persica), and Babool to clean their teeth. In southern India, mango leaf is widely used for cleaning teeth ${ }^{4}$. Tobacco, ash, and salt are also used by many people in rural areas even today. Dental care is a part of primary health care in India; dental care services are available in very few states at the primary health care level. Various factors like demographic behavioral, socio-economic, cultural factors have impact on professional help seeking for dental problems ${ }^{5}$. Utilization of oral health care has been used as an indicator of oral health-care behavior. Regular home oral care and dental checkups are important ${ }^{6}$. For most of the Indians, a visit to a dental office is considered as an extraordinary and an unexpected event. Utilization of healthcare is measured as the number of visits per year or number of people with at least one visit during previous year ${ }^{7}$. The per capita consumption of oral care products in India is around 127 grams, which is very low when compared to China (225 grams), Malaysia(304 grams) and Europe (300 grams). The penetration of oral care products in rural areas is just one third of 
ELK

Asia Pacific Journals

that in urban areas ${ }^{\mathrm{I}}$. The dentist to population ratio is a critically low 1:35000 in the country. This results in low oral hygiene consciousness and widespread dental diseases. In India less than $15 \%$ of the people who use toothpaste brush twice a day. Indian rural oral care market offers huge potential as penetration and per capita consumption of oral care products is very low. However, rising per capita income and increasing awareness is driving demand of oral care products. Consumers have started switching to value-added toothpastes like gels, mouth washes, and teeth whitening products and in rural areas consumers are switching from toothpowders to toothpastes. Colgate and Hindustan Lever together account for over $85 \%$ of the organized toothpaste market. Red and Black toothpowder still accounts for $35 \%$ of the toothpowder market. In toothpowders Colgate and Dabur are the leading players sharing between them $75 \%$ of the market ${ }^{8}$.

\section{ANALYSIS AND INTERPRETATION}

Sample representation:The sample consists of $63 \%$ male and $37 \%$ female. The sample consists of $17 \%$ below 18 years, $35 \%$ youth (between 18 and 35), 30\%

' ideasmakemarket.com/.../study-on-the-oralcare-industry-in-india.html
ELK Asia Pacific Journals - Special Issue

ISBN: 978-81-930411-9-2

middle aged (between 36 and 50), and 18\% old age people (above 50 years of age). There are $18 \%$ of the respondents whose monthly income is below Rs. $3000,43 \%$ between Rs. 3000 and 6000, 27\% between Rs. 6000 and 12,000, 7\% with an income between 12,000 and 30,000 and rest are with a monthly income above Rs. 30,000.The sample comprises of $11 \%$ students, $38 \%$ farmers, $7 \%$ small traders, $7 \%$ private employees, 5\% Govt. employees, 20\% housewives and $12 \%$ with other occupations. In the sample $18 \%$ are illiterates, $25 \%$ are with only primary education, $21 \%$ are with high school education, $15 \%$ are with Intermediate education, rest are graduates, post graduates and above.

The study has shown that $58 \%$ of the people using tooth brush, where as rest are still dependent on traditional methods of brushing/cleaning their teeth. Neem twig is (23\%) used to clean the teeth by majority, but few of them (9\%) are using charcoal/ash and others are using tobacco, brick powder and twigs of some plants. Only $6 \%$ of those who brush daily, are brushing twice a day though $24 \%$ (21 members) them know that it is necessary to brush twice a day. Only $30 \%$ 
ELK

Asia Pacific Journals

of those who use brush are changing their tooth brush once in six months. $17 \%$ of the respondents (25 members) said that they know the formal way of brushing. Colgate and Ajay are the major brands of tooth brush in the selected areas. Price of the tooth brush is the major criterion for selecting a tooth brush. $8 \%$ of the total users who are not using tooth brush are still using Tooth powder. Though tooth paste is the major conjunction used with tooth brush, $36 \%$ of them are using tooth powder at the time of brushing. Colgate is the leading brand in Tooth paste followed by Close-up. Dabur Red is the most preferred tooth powder in Karimnagar district and Farooqui is the leading Tooth powder in Ranga Reddy district. Loyalty is playing a key role in purchasing a tooth paste or tooth powder brand. Strong teeth (42\%) and, white teeth $(32 \%)$ are the major reasons for their loyalty. Only $6 \%$ of the total sample are using tongue cleaner and $2 \%$ said they use mouthwash some times. Nearby grocery store/ retail shop is the place where majority of the respondents buy their dental care products (nearly $85 \%$ ).

When it comes to visiting a dentist, $57 \%$ of the total sample never visited a dentist, $15 \%$ visited only one time, $18 \%$ visited few times
ELK Asia Pacific Journals - Special Issue

ISBN: 978-81-930411-9-2

and only $10 \%$ said they visit a dentist regularly. Among them who visit dentist regularly, $6 \%$ of the total respondents are only visiting the dentist every six months for regular checkups. $46 \%$ of the total respondents said they are suffering from dental problems. Most of those who visited a dentist said it is the tooth ache that made them to visit a dentist. It is interpreted that bad breath, plaque, and gingivitis are not considered as major dental problems by most of the rural people (a physical observation of the interviewer). Even in case of tooth ache majority of the respondents visit a nearby doctor (usually RMP or PMP) first and if it still persists they visit a dentist. Surprisingly $68 \%$ of the respondents, at the end, said that their teeth are strong enough.

Discussion:

The present study shows the dental care habits of rural consumers in Telangana districts. MNCs like HUL, P\&G, ColgatePalmolive and Dabur have reached major parts of the rural areas but still unable create an impact on the dental care habits of the rural consumers. Oral hygiene is not among the priorities of the people. In this context the study suggests the major players of the oral care that there is a need to create awareness about brushing, tooth paste and 
ELK

Asia Pacific Journals

toothpowders among the rural consumers as it benefits both the consumers and corporates. Even today Charcoal and tobacco which cause tooth decay and cancer, are used for cleaning the teeth. Though tooth brush and tooth paste are used by majority, they should know how to choose the tooth brush, paste and other accessories. It is necessary for the government to encourage the good habits related to dental care among the children so that they will have oral health that leads to over all body health. This study primarily concentrated on the major oral care habits and players in the rural Telangana, it is further necessary to go for a cross sectional analysis among different sections of the consumers. At the same time there is a huge scope for the researchers to explore how to capture the untapped markets of rural areas.

\section{REFERENCES:}

[1] Shailee Fotedar, KR Sharma, Vinay Bhardwaj, GM Sogi (2013), "Barriers to the Utilization of Dental services in Shimla, India", European Journal of General Dentistry, 2(5) 139-143

[2] Gambhir, R. S., Brar, P., Singh, G., Sofat, A., \& Kakar, H. (2013).
ELK Asia Pacific Journals - Special Issue ISBN: 978-81-930411-9-2

Utilization of dental care: An Indian outlook. Journal of Natural Science, Biology, and Medicine, 4(2), 292297.

[3] Vallejos-Sanchez AA, Medina-Solis CE, Maupome G, Casanova-Rosado JF, Minaya-Sanchez M, VillalobosRodelo JJ. (2008), Sociobehavioural factors influencing tooth-brushing frequency among schoolchildren. $J$ Am Dent Assoc; 139:743-749

[4] Singh, A., \& Purohit, B. (2011). Tooth brushing, oil pulling and tissue regeneration: A review of holistic approaches to oral health. Journal of Ayurveda and Integrative Medicine, 2(2), 64-68.

[5] Gambhir, R. S., Brar, P., Singh, G., Sofat, A., \& Kakar, H. (2013). Utilization of dental care: An Indian outlook. Journal of Natural Science, Biology, and Medicine, 4(2), 292297.

[6] Lath Vivek, Singh Sopan, Venkanna Babu G, Chhabra Ranit, Rawlani Sudhir, and Khandewal Punit (2013), "Barriers to Restorative Care among the Rural Indian Population of Rajnandgaon District, Chhattisgarh, 
ELK

Asia Pacific Journals

India, Chhattisgarh Journal of

Health, 10(2), pp.12-15

[7] Bommireddy, V. S., Pachava, S.,

Ravoori, S., Sanikommu, S., Talluri,

D., \& Vinnakota, N. R. (2014).

Socio-economic Status, Needs, and

Utilization of Dental Services among

Rural Adults in a Primary Health
ELK Asia Pacific Journals - Special Issue ISBN: 978-81-930411-9-2

Center Area in Southern

India. Journal of International Oral

Health : JIOH, 6(6), 56-60.

[8] Vani, G., Babu, M.G., \&

Panchanatham, N. (2010).

Toothpaste Brands - A study of

Consumer Behavior in Bangalore

City, Journal of Economics and

Behavioral Studies, Vol. 1, No. 1, pp. 27-39 